\title{
A Brief History of Wires in the Brain
}

\author{
Matthew Cobb* \\ School of Biological Sciences, The University of Manchester, Manchester, United Kingdom
}

Metaphors have formed a significant part of the development of neuroscience, often linked with technology. A metaphor that has been widely used for the past two centuries is that of the nervous system being like wires, either as a telegraph system or telephone exchange, or, more recently, in the more abstract metaphor of a wiring diagram. The entry of these terms into scientific writing is traced, together with the insights provided by these metaphors, in particular in relation to recent developments in the study of connectomes. Finally, the place of the wiring diagram as a modern version of Leibniz's "mill" argument is described, as a way of exploring the limits of what insight the metaphor can provide

Keywords: wiring diagram, brain, neuroscience, history, metaphor

\section{INTRODUCTION}

OPEN ACCESS

Edited by:

Giorgio Matassi,

FRE3498 Ecologie et dynamique des systèmes anthropisés (EDYSAN),

France

Reviewed by:

Volker Hartenstein,

University of California, Los Angeles,

United States

Anil K. Seth,

University of Sussex, United Kingdom

*Correspondence:

Matthew Cobb

cobb@manchester.ac.uk

Specialty section:

This article was submitted to Models in Ecology and Evolution, a section of the journal Frontiers in Ecology and Evolution

Received: 17 August 2021 Accepted: 26 November 2021 Published: 16 December 2021

Citation:

Cobb M (2021) A Brief History of Wires in the Brain.

Front. Ecol. Evol. 9:760269. doi: 10.3389/fevo.2021.760269
Our changing understanding of brain function has involved the use of metaphors, often taken from technology (Cobb, 2020). The role of metaphors in science has been studied by philosophers (e.g., Lakoff and Johnson, 1980; Brown, 2003); metaphors shed light on phenomena but also frame and sometimes limit how we can think about them. In this Perspective I explore the metaphor of "wiring" in the brain, the insights it provides and the scientific and conceptual issues raised by this metaphor, some of which go back to 18th century debates and are still unresolved today.

\section{FROM HYDRAULICS TO THE TELEGRAPH}

In the Western tradition, it was thought for millennia that movement was produced by a fluid or spirit in the nerves, coming from the heart or, according to some minority views, the brain. By the 1630s, when it was understood that the heart was merely a pump while the brain was anatomically highly complex, Descartes suggested that movement and brain function occurred through a hydraulic mechanism, similar to that he observed in moving statues in Parisian parks. But sectioning nerves showed there was no such fluid. This left thinkers at a loss; in the 1670s the pioneer microscopist Jan Swammerdam suggested that whatever moved down a nerve might be like a vibration travelling down a plank of wood, but he could not suggest how this might work (Swammerdam, 1758). At the time, most ideas about brain function used mechanical metaphors the term "impression", still in everyday use, implied that stimuli pushed upon the structures of the brain, leaving their shape - an impression. Despite their power and longevity, these ideas failed the basic test of science - there was no evidence for them.

The mastery of electricity in the second half of the 18th century allowed precise experimentation on both isolated nerves and eventually on the brain, leading to new, more informative metaphors regarding brain function. It also had a contradictory effect - because the language of electricity is based on watery metaphors (current, flow, etc.), aspects of our thinking of brain function are pulled back to the old hydraulic metaphors. More significantly, with the development of the telegraph system in the late 1830s a powerful parallel was drawn: the nervous system was described as being 
like a telegraph, while the telegraph system was seen as the nervous system of the country. Both telegraph and nerves involved near-instantaneous communication and they both enabled action.

For the mid-century inventor Alfred Smee, the nervous system was literally telegraphic: "In animal bodies we really have electrotelegraphic communication in the nervous system. That which is seen, or felt, or heard is telegraphed to the brain" (Smee, 1850). Many thinkers suggested that the same kind of stuff was going down both wires and nerves - "intelligence", or as Dr. Spencer Thomson put it: "the wires - nerves - convey the information from all parts of the body" (Thomson and Smith, 1853).

A few years later, in 1863, the great German physiologist Hermann von Helmholtz pointed out that nerves, like telegraph wires, could produce all sorts of functions: "Nerves have often and not unsuitably been compared to telegraph wires. according to the different kinds of apparatus with which we provide its terminations, we can send telegraphic dispatches, ring bells, explode mines, decompose water, move magnets, magnetise iron, develop light, and so on. So with the nerves." (Helmholtz, 1875). Helmholtz argued that the differences in the activity of different parts of the nervous system (for example, different sensory modalities), were not due to what his teacher, Johannes Müller, had called "the law of specific nerve energies". Helmholtz argued that all nerves carried the same kind of signal, and that different sensations arose when the brain interpreted them in different ways.

Thirty years later, Ramon y Cajal used the telegraph network to explain the structure and function of a single neuron: "The nerve cell consists of an apparatus for the reception of currents, as seen in the dendritic expansions and the cell body, an apparatus for transmission, represented by the prolonged axis cylinder, and an apparatus for division or distribution, represented by the nerve terminal arborisation." (Cajal, 1894). Cajal even used wiring as a way of explaining what was happening in the as yet unnamed synapse: "current must be transmitted from one cell to another by way of contiguity or contact, as in the splicing of two telegraph wires" (Robinson, 2001).

Nevertheless, Cajal felt that the telegraph was not a precise model for how the brain worked. Brains were plastic, unlike the fixed telegraph: "A continuous pre-established network a kind of grid composed of telegraph wires in which neither new nodes nor new lines can be created - is something rigid, immutable, incapable of being changed, which clashes with the widespread impression that the organ of thought is, within certain limits, malleable and capable of perfection, above all during its development, by means of well-directed mental exercise." (Cajal, 1894).

\section{FROM SWITCHBOARDS TO WIRING DIAGRAMS}

Toward the end of the 19th century a new technology challenged the rigid telegraph metaphor - the telephone exchange, where messages can be flexibly routed. For French philosopher Henri Bergson "the brain is no more than a kind of central telephonic exchange: its office is to allow communication, or to delay it ...it really constitutes a centre, where the peripheral excitation gets into relation with this or that motor mechanism" (Bergson, 1911). The telephone exchange metaphor is still occasionally used in popular writing - for example, in 2014, Stanislas Dehaene wrote: "consciousness is nothing but the flexible circulation of information within a dense switchboard of cortical neurons" (Dehaene, 2014). However, the limitations of the flexibility seen in a switchboard - they do not even contain simple feedback loops - mean that richer metaphors have often been favoured over the last half century.

In the final years of the 19th century, planning and recording the cabling of a telephone exchange, a telegraph system or even a house led to the appearance of the term "wiring diagram". In 1912 the British surgeon Deane Butcher used the metaphor of wiring in a house to describe the innervation of a muscle cell (Butcher, 1912), while one of the first applications of the term "wiring diagram" to the nervous system came in 1922, by Harvard psychologist Leonard Troland: "From the retina to the brain and hence from the retina to the visual consciousness, the process of seeing depends upon an extremely intricate telegraphic system. It is essential that we should determine the "wiring diagram" of this system for human beings and for any animal species, the visual processes of which we may be studying." (Troland, 1922).

The idea that form can cast light on function gained impetus in the 1940s, following the influential but mistaken suggestion by McCulloch and Pitts (1943) that different forms of synapse expressed what they called "the immanent logic of the nervous system". With the development of computers following the work of von Neumann, itself inspired by the logical concepts outlined by McCulloch and Pitts, the two kinds of wiring diagram that of the animal body and that of the computer - entered into dialogue. McCulloch explained his approach: "regarding the anatomy of the nervous system as if it were a wiring diagram and the physiology of the neuron as if it were a component relay of a computing machine, we shall describe the brain in terms thoroughly familiar to the electrical engineer whose business is communication." (McCulloch and Pfeiffer, 1949).

In the 1950s, the development of early computer models of pattern recognition reinforced the idea of a parallel between wiring in machines and humans. In 1958, psychologist Frank Rosenblatt argued that "if one understood the code or "wiring diagram" of the nervous system, one should, in principle, be able to discover exactly what an organism remembers by reconstructing the original sensory patterns from the "memory traces" which they have left" (Rosenblatt, 1958). Nevertheless, there were clear limits to the precision of the wiring diagram metaphor, because of the plasticity and distributed function of most nervous systems. As Pitts pointed out: "it is never predetermined that a particular cell in a particular place shall project to another particular cell in another particular place, but only that all cells of a given type in a particular locality shall connect (roughly) to cells in another definite locality" (Pitts, 1955).

A more precise version of "wiring diagram" appeared with the advent of valve-based electrical circuits in the early decades of the 20th century. "Circuit diagrams", which represent not 
only wires but also nodes corresponding to precise functions (resistors, diodes, and so on) were soon applied with success to electro-chemical models of neuronal membrane function (e.g., Cole and Curtis, 1939; Stadler, 2017). Circuit diagrams, with their greater detail and implicit focus on function, rather than simply on routing, suggest that the overall function of the circuit may be understandable from structure.

However, until recently there were few worked examples of such interpretations of biological circuit function due to lack of anatomical and biochemical knowledge. For example, Bullock and Horridge (1965), a monumental survey of invertebrate nervous systems, contained few circuit diagrams, which rarely went beyond specifying activation or inhibition at a particular node (this had been a feature of diagrams of the brain since the middle of the 19th century). Bullock and Horridge explained that "little is actually known about specific neuronal connections", but that what was known "understandably encourages the speculation that specified circuits of some complexity are a major principle of neural function. For the most part, this is still a theoretical area”.

To overcome these problems, some researchers focused on extremely simple animal systems in which the organisation and activity of single cells could be precisely described. By 1970, Eric Kandel was using "wiring diagram" to describe his work on the gill withdrawal reflex in Aplysia, both metaphorically and literally (Kandel, 1970). Kandel was able not only to trace the neuronal connections between the various parts of his favourite mollusc, he used circuit diagrams to explain the functional relations between the components. In the hands of Kandel and others, the circuit diagram became simultaneously a metaphor, a description and a hypothesis.

As Cajal and Pitts realised, part of the reason why a wiring diagram - or a circuit - is not an entirely accurate description of the nervous system is that the wires in your house or your computer are fixed with precise connections (or they should be), whereas in its detail the nervous system is imprecise and plastic. Over the last few decades, some researchers have used cloud computing or the internet as metaphors for brain function, with neurons or groups of neurons forming distinct functional subunits carrying out particular computations within a distributed structure (e.g., Cazé et al., 2013). The advantage of this relatively rare metaphor is that it embodies plasticity and distributed function into our conception of the brain, but explaining how exactly that distributed function works in any given case remains a challenge. Furthermore, the limits of this metaphor are quite evident: the internet is designed to function even if key parts it removed, whereas some aspects of brain function can be decisively disrupted if particular areas are damaged.

\section{CONNECTOMES}

The wiring diagram metaphor became particularly widespread with the development of various connectomic projects in the 21st century, even though the article that kicked off the interest in mammalian connectomes (Crick and Jones, 1993) did not refer to wiring diagrams at all. (The term connectome was coined separately by two researchers in 2005 - Hagmann, 2005; Sporns et al., 2005). Connectomic projects, which are aimed at a complete description of the structural connectivity of the central nervous system, can involve very different levels of resolution, depending on whether they focus on neurons or nervous tracts. For example, in 2009 the United States Human Connectome Project, which uses brain scans to describe bundles of nerves that connect brain regions, was claimed to represent "the wiring diagram of the entire, living human brain" (Bardin, 2012). But this map of macroconnections is a distinctly different kind of wiring diagram from the first connectome to be established, the 1986 cell-level description of Caenorhabditis elegans (White et al., 1986) - half-jokingly described by Sydney Brenner's laboratory as "the mind of a worm" (White, 2013). Notably, White et al. (1986) did not use the wiring metaphor once in the 340 pages of their article, preferring "circuitry".

For the moment, there is no sign of either the wiring diagram or circuit diagram metaphor going out of fashion. Even scientists who are critical of the emphasis on connectomics happily use the wiring diagram metaphor (e.g., Barack and Krakauer, 2021; Gomez-Marin, 2021). For the moment there is little reason why these metaphors should be dropped - they serve a useful function for both scientists and the general public, explaining anything from a connectome to a neural network in a simple way and suggesting a link between structure and function. As MIT neuroanatomist Lennart Heimer wrote in 1971: "In order to arrive at a detailed understanding of how the brain works we need a clear knowledge of this wiring diagram. Obviously the diagram itself could not explain the workings of the human mind, but a meaningful picture of the wiring system is a prerequisite for such understanding" (Heimer, 1971).

The limits to the metaphor are those of all biological metaphors - they are not exact descriptions of the phenomena in question. But as long as those who use them realise that there is an inevitable inexactitude at the heart of the image, no harm will be done. For the moment there is no sign of scientists being trapped by the confines of the wiring diagram metaphor, of missing potential insights because of their commitment to the metaphor, probably because "wiring diagram" is intrinsically loose and is recognised as a metaphor, if only for the obvious reason that every biologist knows that neurons are not wires. Future metaphors are hard to predict, because experience suggests they will be based on currently unknown technology. As a word of warning for those with an appetite for new metaphors, use of novel technologies as metaphors has not necessarily led to insight or to broad takeup (e.g., the suggestion that memory functions fractally, like a hologram - Pribram, 1969).

\section{DISCUSSION}

There is a further problem lurking within all representations of the brain, be they metaphorical or literal. In 1974, the psychologist Stuart Sutherland argued that even if we had "a complete wiring diagram of an individual human brain including a specification of the exact probabilities of synaptic transmissions 
occurring at all synapses and everything else necessary to build an exact simulation of the system. (...) it could not be claimed that we had succeeded in understanding how the brain worked; we would merely have succeeded in simulating its workings." (Sutherland, 1974). In 2012 NIH chief Francis Collins complained about the static representations produced by connectome studies: "It'd be like, you know, taking your laptop and prying the top off and staring at the parts inside, you'd be able to say, yeah, this is connected to that, but you wouldn't know how it worked." (Bardin, 2012).

This concern goes back to 1712, when the philosopher Gottfried Leibniz argued that a detailed description of the brain would not explain thought and perception, just as seeing the components of a machine does not explain how it works. This argument, which became known as Leibniz's Mill, has troubled thinkers and scientists down the ages. A wiring diagram on its own will not explain perception or virtually any other part of behaviour - individual differences in synaptic strength and organisation, which do not form part of a simple wiring diagram, can produce individual differences in behaviour (Stern et al., 2017).

In 1946, Yale physicist Roland Meyerott used the wiring diagram metaphor to address this fundamental problem - the link between structure and function:

"Many details of the functioning of the neural units are known, but how, for example, the neural units are combined in the visual area to enable the organism to locate an object seen and to act accordingly is not explained by these observational techniques. It is not likely that a "wiring diagram" of the nervous system of an organism, even if it could be uniquely traced, can ever yield this type of information. Since this is a problem involving space and time intervals, a theory based on the properties of the neural elements will be required in conjunction with a "wiring diagram" in order to explain the behaviour of the organism" (Meyerott, 1946).

The difficulty with using even a highly detailed wiring diagram to accurately predict function can be seen from studies of simple nervous systems. C. elegans worms at the same developmental state produce different changes in the activity of their synapses in response to starvation, leading to different responses (Bhattacharya et al., 2019). This may be partly due

\section{REFERENCES}

Barack, D. L., and Krakauer, J. W. (2021). Two views on the cognitive brain. Nat. Rev. Neurosci. 22, 359-371. doi: 10.1038/s41583-02100448-6

Bardin, J. (2012). Making connections. Nature 483, 394-396. doi: 10.1038/483394a

Bargmann, C., and Marder, E. (2013). From connectome to brain function. Nat. Methods 10, 483-490. doi: 10.1038/nmeth.2451

Barttfeld, P., Uhrig, L., Sitt, J. D., Sigman, M., Jarraya, B., and Dehaene, S. (2015). Signature of consciousness in the dynamics of resting-state brain activity. Proc. Natl. Acad. Sci. 112, 887-892. doi: 10.1073/pnas.1418031112

Bergson, H. (1911). Matter and Memory. London: Allen and Unwin.

Bhattacharya, A., Aghayeva, U., Berghoff, E. G., and Hobert, O. (2019). Plasticity of the electrical connectome of C. elegans. Cell 176, 1174-1189. doi: 10.1016/j.cell. 2018.12.024 to subtle differences in individual connectomes that emerge during development (Witvliet et al., 2021). The circuit composed of 30-odd neurons that is found in the lobster's stomach can produce radically different behaviours, while the same behaviour can be produced by very different circuits (Bargmann and Marder, 2013). At the other end of the scale of brain complexity, human brains show the same physical connectivity but different functional configurations under anaesthesia and when awake (Barttfeld et al., 2015).

In other words, wiring diagrams, no matter how complex, are not enough. The issue highlighted by Meyerott remains: we need a theory - or theories - to explain how neural networks function. Our current theoretical approaches have been shaped by the metaphor that has dominated our thinking about the brain since the 1950s, which is that the brain is something like a computer, carrying out computations that enable it to model the present and predict the consequences of actions on future states (Cobb, 2020). This metaphor clearly involves the "wiring diagram" metaphor described here, with all its power and limits. But a distinction between the two metaphors is beginning to emerge - although "wiring diagram" retains its influence, over the last decade or so some neuroscientists have become increasingly uneasy with this starting point, expressing frustration at the wave of anatomical, genetic and electrophysiological data we are collecting without a theoretical framework (e.g., Sporns, 2015; Churchland and Abbott, 2016; Frégnac, 2017). Starting at the "top", trying to develop a theory to explain the functioning of the wiring diagram of the human or mammalian brain, seems to me to be an error. Instead, we should attempt to develop such a theory by studying small networks where we can know the precise structural, functional and effective connectivity at a cellular level and study their function using theoretical models (e.g., Friston et al., 2013). Applying such a theory to the wiring diagram of ourselves will be an immense challenge - the work of centuries, I expect. Our current inability to understand the function of the wiring in the lobster's stomach - or in the worm, or in the maggot's brain - is a measure of the task before us.

\section{AUTHOR CONTRIBUTIONS}

MC conceived and wrote the article.

Brown, T. (2003). Making Truth: Metaphor in Science. Chicago: University of Illinois Press.

Bullock, T. H., and Horridge, A. (1965). Structure and Function in the Nervous Systems of Invertebrates. San Francisco: W. H. Freeman.

Butcher, W. D. (1912). The education of the brain as an electric organ. J. Rönt. Soc. 8, 76-90. doi: 10.1259/jrs.1912.0046

Cajal, S. (1894). The Croonian lecture - la fine structure des centres nerveux. Proc. Roy. Soc. Lond. 55, 444-468. doi: 10.1098/rspl.1894.0063

Cazé, R., Humphries, M., and Gutkin, B. (2013). Passive dendrites enable single neurons to compute linearly non-separable functions. PLoS Comp. Biol. 9:e1002867. doi: 10.1371/journal.pcbi.1002867

Churchland, A., and Abbott, L. (2016). Conceptual and technical advances define a key moment for theoretical neuroscience. Nat. Neurosci. 19, 348-349. doi: $10.1038 / \mathrm{nn} .4255$

Cobb, M. (2020). The Idea of the Brain: a History. London: Profile. 
Cole, K. S., and Curtis, H. J. (1939). Electric impedance of the squid giant axon during activity. J. Gen. Physiol. 22, 649-670. doi: 10.1085/jgp.22.5.649

Crick, F. H. C., and Jones, E. (1993). Backwardness of human neuroanatomy. Nature 361, 109-110. doi: 10.1038/361109a0

Dehaene, S. (2014). Consciousness and the Brain: Deciphering how the Brain Codes Our Thoughts. New York: Penguin.

Frégnac, Y. (2017). Big data and the industrialization of neuroscience: a safe roadmap for understanding the brain? Science 358, 470-477. doi: 10.1126/ science.aan 8866

Friston, K., Moran, R., and Seth, A. K. (2013). Analysing connectivity with granger causality and dynamic causal modelling. Curr. Opin. Neurobiol. 23, 172-178. doi: 10.1016/j.conb.2012.11.010

Gomez-Marin, A. (2021). Promisomics and the short-circuiting of mind. eNeuro 8:ENEURO.0521-20.2021. doi: 10.1523/ENEURO.0521-20.2021

Hagmann, P. (2005). From Diffusion MRI to Brain Connectomics. PhD Thesis. Lausanne: ePFl.

Heimer, L. (1971). Pathways in the brain. Sci. Am. 225, 48-64. doi: 10.1038/ scientificamerican0771-48

Helmholtz, H. (1875). On the Sensations of Tone as a Physiological Basis for the Theory of Music. London: Longmans, Green. doi: 10.1037/10838-000

Kandel, E. R. (1970). Nerve cells and behaviour. Sci. Am. 223, 57-71. doi: 10.1038/ scientificamerican $0770-57$

Lakoff, G., and Johnson, M. (1980). Metaphors We Live By. Chicago: University of Chicago Press.

McCulloch, W. S., and Pfeiffer, J. (1949). Of digital computers called brains. Sci. Monthly 69, 368-376.

McCulloch, W., and Pitts, W. (1943). The immanent logic of the nervous system. Bull. Math. Biophys. 5, 115-133. doi: 10.1007/BF02478259

Meyerott, R. E. (1946). Mathematical biophysics of the central nervous system. Am. J. Sci. 244, 865-866.

Pitts, W. (1955). "Comments on session on learning machines," in Proceedings of the March 1-3, 1955, Western Joint Computer Conference, 108-111. New York, NY: Association for Computing Machinery doi: 10.1145/1455292.1455313

Pribram, K. (1969). The neurophysiology of remembering. Sci. Am. 220, 73-86. doi: 10.1038 /scientificamerican0169-73

Robinson, J. (2001). Mechanisms of Synaptic Transmission: Bridging the Gaps (1890-1990). Oxford: Oxford University Press. doi: 10.1093/acprof:oso/ 9780195137613.001.0001

Rosenblatt, F. (1958). The Perceptron: a probabilistic model for information storage and organization in the brain. Psychol. Rev. 65, 386-408. doi: 10.1037/ h0042519

Smee, A. (1850). Instinct and Reason Deduced from Electro-Biology. London: Reeve, Benham and Reeve. doi: 10.1037/12035-000

Sporns, O. (2015). "Network neuroscience," in The Future of the Brain: Essays by the World's Leading Neuroscientists, eds G. Marcus and J. Freeman (Oxford: Princeton University Press), 90-99. doi: 10.1515/97814008519 35-012
Sporns, O., Tononi, G., and Kötter, R. (2005). The human connectome: a structural description of the human brain. PLoS Comp. Biol. 1:e42. doi: 10.1371/journal. pcbi.0010042

Stadler, M. (2017). "Circuits, algae, and whipped cream: the biophysics of nerve, ca. 1930," in The History of the Brain and Mind Sciences: Technique, Technology, Therapy, eds S. T. Casper and D. Gavrus (Rochester NY: Boydell \& Brewer). doi: $10.1017 / 9781787440159.005$

Stern, S., Kirst, C., and Bargmann, C. I. (2017). Neuromodulatory control of long-term behavioral pattenrs and individuality across development. Cell 171, 1649-1662. doi: 10.1016/j.cell.2017.10.041

Sutherland, N. S. (1974). "Computer simulation of brain function," in Philosophy of Psychology, ed. S. C. Brown (London: Macmillan Education). doi: 10.1007/9781-349-02110-9_13

Swammerdam, J. (1758). The Book of Nature. London: Seyffert.

Thomson, S., and Smith, H. (1853). A Dictionary of Domestic Medicine and Household Surgery. Philadelphia: Lippincott.

Troland, L. T. (1922). The present status of visual science. Bull. Nat. Res. Coun. 5, $1-120$.

White, J. G. (2013). "Getting into the mind of a worm-a personal view (June 25, 2013)," in WormBook, ed. The C. elegans Research Community. doi: 10.1895/ wormbook.1.158.1

White, J. G., Southgate, E., Thomson, J. N., and Brenner, S. (1986). The structure of the nervous system of the nematode Caenorhabditis elegans. Philos. Trans. R. Soc. Lond. B 314, 1-340. doi: 10.1523/jneurosci.11-01-00001. 1991

Witvliet, D., Mulcachy, B., Mitchell, J. K., Meirovitch, Y., Merger, D. R., $\mathrm{Wu}, \mathrm{Y}$., et al. (2021). Connectomes across development reveal principles of brain maturation. Nature 596, 257-261. doi: 10.1038/s41586-02103778-8

Conflict of Interest: The author declares that the research was conducted in the absence of any commercial or financial relationships that could be construed as a potential conflict of interest.

Publisher's Note: All claims expressed in this article are solely those of the authors and do not necessarily represent those of their affiliated organizations, or those of the publisher, the editors and the reviewers. Any product that may be evaluated in this article, or claim that may be made by its manufacturer, is not guaranteed or endorsed by the publisher.

Copyright $\odot 2021$ Cobb. This is an open-access article distributed under the terms of the Creative Commons Attribution License (CC BY). The use, distribution or reproduction in other forums is permitted, provided the original author(s) and the copyright owner(s) are credited and that the original publication in this journal is cited, in accordance with accepted academic practice. No use, distribution or reproduction is permitted which does not comply with these terms. 